\title{
A Systematic Literature Review: Constructivism in Multidisciplinary Learning Environments
}

\section{Merve KARA}

Bahçeşehir University

\begin{abstract}
This study represents a review of literature on constructivism used in multidisciplinary learning environments which is to uncover the usage rate of constructivism in multidisciplinary environments and to be a guide to those who are seeking further knowledge about this topic in the future. Aspects like publication date and learner categories were taken into consideration during the research. It includes the definition of constructivism, the usage progress of constructivism in the classroom through the years, the best age range which can easily adapt the constructivist approach, types of activities, and the advantages and disadvantages of the approach in the multidisciplinary classroom. 64 articles were surveyed and 30 articles were selected to analyze. The data obtained showed that there is a significant increase in using a constructivist approach in every kind of classroom. However, some of the articles revealed that there are also a small number of disadvantages, too.
\end{abstract} Submitted

02.02.2019 Revised

17.04.2019

Accepted

22.04.2019

Keywords: constructivism, multidisciplinary, education, STEM.

\section{Suggested Citation:}

Kara, M. (2019). A Literature Review: The Usage of Constructivism in Multidisciplinary Learning Environments, International Journal of Academic Research in Education, 4(1-2), 19-26. DOI: 10.17985/ijare.520666

\footnotetext{
${ }^{1}$ Bahçeşehir University, merve.kara2@bahcesehir.edu.tr
} 


\section{INTRODUCTION}

Constructivism is obviously the most dominant approach to education in this century (Krahenbuhl, 2016). In recent years, it seems to affect deeply the teaching and learning process. In the study, the application of constructivist learning theory into multidisciplinary learning environments are also examined (Basturk, 2016). Related studies have shown that using constructivism in different disciplines and inter-disciplinary fields have been considerably increasing (Jaleel \& Verghis, 2015). For example, teachers started to prepare lesson plans that include problem-solving which is one of the main elements of constructivism (Basturk, 2016). Designed plans should challenge learners to think that how can they use the given knowledge more effectively in the real world (Savery \& Duffy, 1995). Moreover, STEM instructors are creating safe environments where the learners feel free to question and reflect it to the learning process (Ah-Nam \& Osman, 2017). Using constructivist approach in the STEM classes will be even more common throughout the years.

This paper presents a systematic literature review of the usage of constructivism in multidisciplinary learning environment. The segments below introduce a brief definition of systematic literature review methodology.

\subsection{Systematic Literature Review}

A systematic review is an exhaustive analysis of every study that is related and selected to be reviewed in order to find an answer to a certain question (Jesson et al., 2011) In this article, a systematic literature review was used to identify the effects of the constructivism approach when it is used in multidisciplinary lessons. During the review two separate themes emerged: constructivism and multidisciplinary learning environments. Both of the themes will be explained separately and together in the following sections.

\subsection{Purpose of the study}

The aim of this study is to reveal how broad this situation is in terms of age range and different disciplines (Gunduz \& Hursen, 2015). To facilitate the searching process, the following questions are taken into consideration:

Research Question 1. What kind of changes happened over the years about using constructivism in the classroom?

Research Question 2. What is the age range selected in the studies that the constructivist approach used in the multidisciplinary learning environment? (K-12, talk about kindergarten, primary, secondary, high school, higher education)

Research Question 3. How can constructivist approach be applied in multidisciplinary learning environments?

Research Question 4. What are the advantages of using a constructivist approach in multidisciplinary learning environments?

Research Question 5. What are the disadvantages of using a constructivist approach in multidisciplinary learning environments? 


\subsection{What is constructivism?}

According to Driscoll (2005), "Knowledge is constructed by learners as they attempt to make sense of their experiences" (p.387). Constructivists emphasize that to be able to acquire knowledge, it is necessary to experience that knowledge personally (Driscoll, 2005). They also underline that knowledge must be based on experience to understand any kind of information (Thompson, 2018). In constructivist learning, "process of learning" has more importance than "the products of learning" (Amineh \& Asl, 2015). The constructivist approach defends that information which learners can effectively utilize should be improved. So to be an active learner (life-long learner) is highly important in order to acquire the intended instruction. Learners also responsible for what and how are they going to learn the new knowledge (Jaleel \& Verghis, 2015). Driscoll said that instructors should provide the learners with "an opportunity to explore and learn something of personal interest" (p.391). In a constructivist classroom, every learner should be able to participate effectively, and to construct the knowledge the environment should be flexible and student-based (Gomleksiz \& Elaldi, 2011).

\subsection{Multidisciplinary learning environments}

In this century, learning skills and qualifications have to show a difference than before due to the new world views. Critical thinking, collaboration, creativity and communication fields are the important parts of $21^{\text {st }}$ century learning skills. Getting qualifications of different disciplines is a popular way to reach the needs of the era (Mercimek et al., 2016). STEM teaching, which is based on teaching the disciplines of science, technology, engineering and mathematics, is gaining importance at this point.

A study by Glancy and Moore (2013) states that the researches of John Dewey had an impact on multidisciplinary areas, like the STEM. As these fields, together, become popular, new inter-disciplinary teaching strategies begin to emerge (Glancy \& Moore, 2013). The strategies such as case-based or problem-based learning may boost the academic results of the learner (Gijbels et al., 2006). The instructors are responsible for creating the learning environments, they are just the facilitators. As the teacher produces great work, the educational outcomes will be worth mentioning, like Prensky (2003) said: "a motivated learner cannot be stopped".

\subsection{Constructivism in different learning environments}

As previously mentioned, to acquire knowledge, the learner should associate the given information with a real situation. So students should be given opportunities for inter-disciplinary learning in order to deal with actual life complications (Kamphorst, 2018). Moreover, content-rich lessons have a clear effect on learners' acquiring knowledge process and implementing to their understanding (Hendry et al., 2017). For instance, to teach the learners how to think critically, to develop reasoning skills, in a mathematics class, the instructor should use various materials (Dewi \& Harahap, 2016), or in a science lesson, to measure the acquisition level, the emphasis should be placed on learning activities (Hartle et al., 2012).

To facilitate the learners' process of learning might be the most sacred duty of the teachers such as leading the learners to deeper information or letting them choose the background, tool, method which are the elements of creativity during an art class while painting a certain subject matter (Thompson, 2015). Furthermore, constructivism also requires individualized learning, to give an example, in a music class, if a student loves listening to heavy metal, we cannot expect him/her to find playing harp breathtaking (Shively, 2015). In The Common European Framework of Reference for Languages, there are some important concepts such as life-long learning, self-learning and learning the learning process in terms of the constructivism approach. Hence, because the learner not only makes decisions about language learning but also the need to evaluate the language development process itself (Gomleksiz \& Elaldi, 2011).

Apparently, constructivism provides a wide scale of learning experiences for learners and a remarkable professional growth for teachers (Marlow \& McLain, 2011). 


\section{METHOD}

\subsection{The article selection process}

Content analysis is used to analyze the data in the articles. (Gunduz \& Hursen, 2015). During the review of literature, a variety of techniques adopted in order to select the articles.

The inclusion criteria: English and Turkish language. Articles published between 1990 and 2018 from BAU (Bahcesehir University) library, EBSCO, and Education Resources Information Center (ERIC) were taken into consideration. Keywords such as constructivism, multidisciplinary, learning environments and STEM were used in the process of reviewing under the educational research categories.

The exclusion criteria: Papers published before 1990. Kindergarten. Adult learning. E-learning

For the research parameters, as the kind of document "article" and "pdf" format, and as the language "all languages" were chosen (Akçayır \& Akçayır, 2017).

\subsection{The data analysis process}

Every study was analyzed by only one researcher. The first two questions are about publication year and learner type. Studies have shown that using constructivism with every discipline is suitable for every age range. However, as the student ages, due to the stereotyped world views, the creativity fades. So most of the studies have been made regarding K-12 students due to their creativity level. About the last two questions (advantages and disadvantages), all data collected from the articles' recommendations, discussions and conclusions parts (Akçayır \& Akçayır, 2017).

\section{RESULTS AND DISCUSSION}

\subsection{What kind of changes happened over the years about using constructivism in the classroom?}

Using the constructivist approach in every discipline becomes important more and more in the current century (Ah-Nam \& Osman, 2017). Although it is hard to embrace the changing positions of instructors and learners, constructivist environments, which let the learners get into social interaction and acquire information, provide opportunities to a plain transformation (Akar \& Yıldırım, 2005). Through the years, the constructivist view of learning helped not only the learning process, but it has an immense contribution to teachers' self-development (Le Cornu \& Peters, 2009). As the usage of constructivism increases, the roles of teachers and learners have become more significant, such as teacher as a facilitator and learners as the explorers who seek knowledge on their own (Liu \& Chen, 2010). This suggests that teachers also to be the explorers; to create an environment that students can explore within is a tough mission to be accomplished. Hence, teachers will improve themselves day by day as they create a brand new environment and more studies about using constructivist approach will be published with more experience.

\subsection{What is the age range selected in the studies that the constructivist approach used in the multidisciplinary learning environment?}

In more than half of the articles cited from, K-12 students, (age 7-18), were selected as the age range. Higher education has the second most usage of constructivism in the classroom. There are not many 
articles especially about constructivism in the kindergarten, however, it is highly recommended as social interaction has great importance in terms of "peer culture" which occurs when the little learner build and share information through activities in the created learning environment by the teacher (Lash, 2008).

\subsection{How can constructivist approach be applied in multidisciplinary learning environments?}

When we say the application of constructivism in different learning environments, several methods and techniques we use come to our mind; which are the experience gained by the learners. There are several constructivist conditions for learning to be occurred:

a. Complex and relevant learning environments: the simplification of the assignments will prevent the learners from solving a problem, so the students should deal with a complex situation.

b. Social Interaction: to improve the cognitive process, the learner should interact with other students, they should see another point of views. For instance, collaborative learning can be used in the classroom as an activity - make two groups, give them two different topics, let them search and talk for a while, then unite the groups and give one of the previous topic to the whole class, half of them will be quite eager to convey what they have learned (Mvududu \& Thiel-Burgess, 2012).

c. Multiple perspectives and multiple modes of learning: to use different kinds of tools of visual or auditory will make the learners to see different aspects of the same content.

d. Ownership in learning: determining what and how are they going to learn the new knowledge

e. Self-awareness of knowledge construction: to learn the process of learning (Driscoll, 2005).

\subsection{What are the advantages of using a constructivist approach in multidisciplinary learning environments?}

According to the articles, there are many advantages of constructivism in the classroom. Briefly, it helps the learner to develop a higher cognitive level which is to build on the knowledge they have already know (Mayer, 2006). Learners are also involved in their own learning by acquiring knowledge through a real-life experience which is a great way to transfer their already known knowledge right into the situation (Steakley, 2008). Students construct conceptive ground in order to study with further disciplines in a welldesigned multidisciplinary learning environment (Khuzzan \& Goulding \& Rahimian, 2015). One of the most mentioned advantages of using constructivism in the articles is to form a new knowledge which is a way to help the learner feel that he/she is one of the members of this world and a part of earth's history (Jaleel \& Verghis, 2015). As mentioned before, constructivist approach provides experience to the students in every kind of learning environment, it teaches through the motto "learning by doing it".

\subsection{What are the disadvantages of using a constructivist approach in multidisciplinary}

\section{learning environments?}

Among the articles reviewed, some disadvantages of using a constructivist approach in a multidisciplinary environment are found. The numbers of negative articles are quite low. Here are the several disadvantages: Constructivism's complexity makes it hard for anyone to think it as a whole, to create a consistent thought of the definition of the constructivism and then to simplify it become quite difficult without a properly designed lesson (Gordon, 2009). Moreover, constructivist teaching strategies require expert teachers in terms of pedagogy, however, teachers are not prepared for the constructivist teaching, they should be able to see what their student need and make the required alteration (Gordon, 2009). Especially in developing countries, there is not an education for teachers to prepare them for the future. The faculties 
give no more than thick books. Despite the fact that to be a good teacher, experience and creativity is essential, the newly graduated teachers find themselves faced with almost 20 pairs of eyes, in a small classroom, trying to hold them down. The teachers and the education system itself should be well-prepared in order to teach well.

\section{CONCLUSION}

Constructivism in the classroom has a long history in educational studies. However, it can be seen as an infant in the multidisciplinary learning environment. With the rise of STEM or STEAM, and the collaborative studies, the difference is rapidly closing. The future research would be about the required expertise of teacher who wants to be a constructivist.

In order to acquire the 21st century skills, the students are expected to have a word in teaching, have the skills of problem solving and critical thinking by conducting research within the framework of their interests and are able to create a product in the learning process by using different disciplines together. This study focused on the studies that include constructivist approach usage in multidisciplinary lessons which lets self-learning to emerge. There is a lack of research on constructivism in STEM learning; however this study motivates to conduct further research on using constructivism in STEM environments.

It is certain that using the constructivist approach is highly effective in terms of cognitive process, selflearning based on experience, and to be part of the global population, to contribute the world knowledge heritage. However, like in every approach (there is no such thing as the perfect learning method), there are a few disadvantages such as lack of expert constructivist teacher, the difficulty of preparing a constructivist lesson and the complexity of the design.

While comparing the advantage and the challenges of the approach, it is obvious that odds are in using constructivism in a multidisciplinary learning environment. Overall, in the future, it is certain that there will be more studies about the particular subject matter.

the relevant literature. Discuss your research finding with the relevant literature. Discuss your research finding with the relevant literature. Discuss your research finding with the relevant literature.

\section{References}

Ah-Nam, L., \& Osman, K. (2017). Developing 21st Century Skills through a Constructivist-Constructionist Learning Environment. K-12 STEM Education, 3(2), 205-216.

Akar, H., \& Yıldırım, A. (2005). Challenges of introducing a constructivist classroom culture in a predominantly teacher-centered environment.

Akçayır, M., \& Akçayır, G. (2017). Advantages and challenges associated with augmented reality for education: A systematic review of the literature. Educational Research Review, 20, 1-11.

Amineh, R. J., \& Asl, H. D. (2015). Review of constructivism and social constructivism. Journal of Social Sciences, Literature, and Languages, 1(1), 9-16.

Basturk, S. (2016). Primary Pre-Service Teachers' Perspectives on Constructivism and Its Implementation in the Schools. Universal Journal of Educational Research, 4(4), 904-912.

Dewi, I., \& Harahap, M. S. (2016). The Development of Geometri Teaching Materials Based-on Constructivism to Improve the Students' Mathematic Reasoning Ability through Cooperative 
Learing Jigsaw at the Class VIII of SMP Negeri 3 Padangsidimpuan. Journal of Education and Practice, 7(29), 68-82.

Driscoll, M. P. (2005). Psychology of learning for instruction.

Gijbels, D., Van De Watering, G., Dochy, F., \& Van Den Bossche, P. (2006). New learning environments and constructivism: The students' perspective. Instructional Science, 34(3), 213-226.

Glancy, A. W., \& Moore, T. J. (2013). Theoretical foundations for effective STEM learning environments.

Gomleksiz, M. N., \& Elaldi, ş. (2011). Yapılandırmacı Yaklaşım Bağlamında Yabancı Dil Öğretimi. Electronic Turkish Studies, 6(2).

Gordon, M. (2009). Toward a pragmatic discourse of constructivism: Reflections on lessons from practice. Educational Studies, 45(1), 39-58.

Gunduz, N., \& Hursen, C. (2015). Constructivism in Teaching and Learning; Content Analysis Evaluation. Procedia-Social and Behavioral Sciences, 191, 526-533.

Hartle, R. T., Baviskar, S., \& Smith, R. (2012). A Field Guide to Constructivism in the College Science Classroom: Four Essential Criteria and a Guide to their Usage. Bioscene: Journal of College Biology Teaching, 38(2), 31-35.

Hendry, A., Hays, G., Challinor, K., \& Lynch, D. (2017). Undertaking Educational Research Following the Introduction, Implementation, Evolution, and Hybridization of Constructivist Instructional Models in an Australian PBL High School. Interdisciplinary Journal of Problem-Based Learning, 11(2), 7.

Jaleel, S., \& Verghis, A. M. (2015). Knowledge creation in constructivist learning. Universal Journal of Educational Research, 3(1), 8-12.

Jesson, J., Matheson, L., \& Lacey, F. M. (2011). Doing your literature review: Traditional and systematic techniques. Sage.

Kamphorst, J. C. (2018). Multidisciplinary Cooperation by Students in a European University of Applied Sciences. Journal of University Teaching and Learning Practice, 15(1), 5.

Khuzzan, S. M. S., Goulding, J. S., \& Rahimian, F. P. (2015). Purposive teaching styles for transdisciplinary AEC education: A diagnostic learning styles questionnaire. International Journal of Architectural Research: ArchNet-IJAR, 9(2), 98-112.

Krahenbuhl, K. S. (2016). Student-centered education and constructivism: Challenges, concerns, and clarity for teachers. The Clearing House: A Journal of Educational Strategies, Issues, and Ideas, 89(3), 97-105.

Lash, M. (2008). Classroom community and peer culture in kindergarten. Early Childhood Education Journal, 36(1), 33-38.

Le Cornu, R., \& Peters, J. (2009). Towards constructivist classrooms: the role of the reflective teacher. The Journal of Educational Enquiry, 6(1).

Liu, C. C., \& Chen, I. J. (2010). Evolution of constructivism. Contemporary Issues in Education Research, $3(4), 63-66$.

Marlow, M. P., \& McLain, B. (2011). Assessing the Impacts of Experiential Learning on Teacher Classroom Practice. Research in Higher Education Journal, 14.

Mayer, M. M. (2006). The effect of constructivist learning environments on student learning in an undergraduate art appreciation course (Doctoral dissertation, University of North Texas). 
Mercimek, B., \& Kelek, A. \& Kuzu, A. (2016). Eğitimde STEM Kullanımı ve Sağlayacağı Katkıların Öğrenci, Öğretmen ve Öğretim Programları Açısından Değerlendirilmesi. Eğitim Teknolojileri Okumaları.

Mvududu, N. H., \& Thiel-Burgess, J. (2012). Constructivism in practice: The case for English language learners. International Journal of Education, 4(3), 108-118.

Prensky, M. (2003). Digital game-based learning. Computers in Entertainment (CIE), 1(1), $21-21$.

Savery, J. R., \& Duffy, T. M. (1995). Problem-based learning: An instructional model and its constructivist framework. Educational Technology, 35(5), 31-38.

Shively, J. (2015). Constructivism in music education. Arts Education Policy Review, 116(3), 128-136.

Steakley, M. E. (2008). Advantages, Disadvantages, and Applications of Constructivism. https://www.slideshare.net/mesteakley/advantages-disadvantages-and-applications-ofconstructivism

Thompson, C. M. (2015). Constructivism in the art classroom: Praxis and policy. Arts Education Policy Review, 116(3), 118-127.

Thompson, Penny. (2018). Foundations of educational technology. Retrieved from https://epress.library.okstate.edu/catalog/foundations-of-educational technology/foundationsof-educational-technology-2018.pdf 